University of Wollongong

Research Online

Faculty of Informatics - Papers (Archive)

Faculty of Engineering and Information

Sciences

October 2000

\title{
Establishment of typical harmonic voltage levels in radial distribution systems
}

D. A. Robinson

University of Wollongong, duane@uow.edu.au

V. J. Gosbell

University of Wollongong, vgosbell@uow.edu.au

B. S. Perera

University of Wollongong

D. J. Mannix

University of Wollongong

Follow this and additional works at: https://ro.uow.edu.au/infopapers

Part of the Physical Sciences and Mathematics Commons

\section{Recommended Citation}

Robinson, D. A.; Gosbell, V. J.; Perera, B. S.; and Mannix, D. J.: Establishment of typical harmonic voltage levels in radial distribution systems 2000.

https://ro.uow.edu.au/infopapers/225

Research Online is the open access institutional repository for the University of Wollongong. For further information contact the UOW Library: research-pubs@uow.edu.au 


\title{
Establishment of typical harmonic voltage levels in radial distribution systems
}

\author{
Abstract \\ This paper reports on a simple method to identify problem areas with relation to harmonic distortion \\ within radial distribution systems at the planning stage. The purpose of the work is to produce a simple \\ method of establishing harmonic distortion levels throughout a study distribution system when only \\ limited system data and load information is available. The preliminary work presented in this paper is \\ aimed at establishing useful planning guidelines for utilities to help with the analysis of harmonics in \\ medium voltage (MV) distribution systems during the design phase. Harmonic analysis during the design \\ of a distribution system is seen as an important step in controlling harmonic distortion levels. \\ Disciplines \\ Physical Sciences and Mathematics

\section{Publication Details} \\ This paper originally appeared as: Robinson, DA, Gosbell, VJ, Perera, BSP \& Mannix, DJ, Establishment of \\ typical harmonic voltage levels in radial distribution systems, Proceedings. Ninth International Conference \\ on Harmonics and Quality of Power, 1-4 October 2000, vol 3, 1053-1058. Copyright IEEE 2000.
}




\title{
ESTABLISHMENT OF TYPICAL HARMONIC VOLTAGE LEVELS IN RADIAL DISTRIBUTION SYSTEMS
}

\author{
D.A. Robinson, V.J. Gosbell, Member IEEE, B.S.P. Perera, Member IEEE, D.J. Mannix \\ Integral Energy Power Quality Centre \\ University of Wollongong, NSW, 2522, Australia
}

\begin{abstract}
This paper reports on a simple method to identify problem areas with relation to harmonic distortion within radial distribution systems at the planning stage. The purpose of the work is to produce a simple method of establishing harmonic distortion levels throughout a study distribution system when only limited system data and load information is available. The preliminary work presented in this paper is aimed at establishing useful planning guidelines for utilities to help with the analysis of harmonics in Medium Voltage (MV) distribution systems during the design phase. Harmonic analysis during the design of a distribution system is seen as an important step in controlling harmonic distortion levels.
\end{abstract}

Keywords: power quality, harmonic distortion, power system harmonics, planning

\section{INTRODUCTION}

With many customer loads being sensitive to excessive harmonic voltage distortion, electricity distribution utilities should now be looking towards preventative measures to ensure that voltage distortion levels are within limits set by the appropriate standards [1]. Measures will need to be taken at the planning stage to ensure that the distribution systems will be able to meet harmonic standards as load distortion rises.

The work to be described here arises out of a project to develop distribution system planning guidelines to enable the design engineer to maximise the harmonic capabilities of a distribution system. This can be achieved by optimising parameters such as impedance values of lines and transformers, feeder lengths, allocation of load types to particular connection points, location and size of power factor correction capacitors, and connection of detuning reactors.

The problem of estimating harmonics at the design stage of a distribution system is very different to the normal investigation of a particular harmonic load. The study must encompass many loads generating harmonics and whose harmonic spectrum and daily variation are poorly specified. The aim is not to accurately model every individual load but to determine methods for representing the statistics of large aggregations of load.

This paper will report on a method that can be used to establish typical harmonic distortion levels within a distribution system and therefore predict the effect of a change in networks or load conditions. The method applies to medium voltage (MV) radial distribution systems and incorporates background distortion from the upstream supply.
Harmonic distortion surveys that have been completed over the past decade have shown the $5^{\text {th }}$ harmonic is the most significant harmonic and usually accounts for over $80 \%$ of the total harmonic distortion (THD) within MV systems [2-4]. This is due to the rapid fall off of harmonics with frequency produced by present power electronic technology (even more rapid than the fall off of voltage limits) and the removal of most $3^{\text {rd }}$ harmonics by delta/star transformers stepping down to the LV system. Present trends suggest that the $5^{\text {th }}$ harmonic will continue to dominate for many years. A key assumption in this paper is that if the $5^{\text {th }}$ harmonic voltage is within acceptable limits, there will be no harmonic problems. This assumption will need to be revisited where there are power factor correction capacitors giving amplification of other frequencies.

It will be further assumed that the loads on a feeder can be classified as residential (R), industrial (I) and commercial (C) types, each having an average harmonic characteristic that can be obtained by a one-off simple measurement. The method to be described is easy to set up in a spreadsheet and allows easy calculation of sensitivities to various planning parameters so that the important ones can be identified.

The project also involved a harmonic survey of seven sites on an MV distribution system. A small part of the measurements have been used to give the parameters of the three load types. The rest of the survey results have been used to validate the proposed method.

\section{IEC 61000.3.6 HARMONIC STANDARD}

The method for establishing harmonic levels within a distribution system uses some of the concepts that are given in IEC 61000.3.6, a harmonic limit standard for MV and LV systems which is soon to be adopted by Australia and New Zealand. Two concepts used in this paper are the evaluation of emission levels by statistical means and the second summation law.

Emission Levels - The standard suggests that the emission levels of harmonic voltage distortion should be evaluated using a statistical approach to take time variations into account [1]. Broadly, it is proposed that a harmonic survey should be taken over a period of at least a week and that the signal analysis should be along the strict guidelines of [IEC 61000.4.7] with the measurement classified and the $95^{\text {th }}$ percentile of the cumulative probability distribution (CP95) 
determined. The resulting value must be less than the planning level for the appropriate voltage level, of which suggested values are given. This prevents a utility being penalised for a high value of harmonics that might occur for only $5 \%$ of the day ( 1.2 hours).

Second Summation Law - The law is used to combine the $95 \%$ cumulative probability values of hamonic currents or voltages to give their overall combined value. It is designed to give a value less than that which would be given by direct addition to take account of time diversity.

Consider the data sets in Table 1, where the first set has 90 values of " 1 ", followed by 5 of " 2 " and then 5 of " 3 " giving a $95 \%$ cumulative value of 2 . The second set shown will have a $95 \%$ cumulative value of 3 . The sum of these two sets will have 100 values all of " 4 " giving a CP95 value of 4 , yet the sum of the individual CP95 values is 5 .

A summation power law is assumed to have the form

$$
V_{h}=\sqrt[a]{\sum V_{h i}^{a}}
$$

where

$V_{h}=$ magnitude of resulting harmonic voltage (order $h$ )

$V_{h i}=$ magnitude of individual harmonic voltage $i$ (order $h$ ) to be combined.

$a=$ exponent depending on the probability of actual value exceeding the calculated value and the degree to which the individual harmonic voltages vary in magnitude and phase.

For the above example, $a$ should be 1.51. For the $5^{\text {th }}$ harmonic it is suggested by [1] that $a=1.4$ be used, with a higher value for some of the higher harmonics.

Table 1

Example Values of Sampled Data

\begin{tabular}{|l|c|c|c|}
\hline \% of Data & Set 1 & Set 2 & Sum (set 1+set 2) \\
\hline $90 \%$ & 1 & 3 & 4 \\
\hline $5 \%$ & 2 & 2 & 4 \\
\hline $5 \%$ & 3 & 1 & 4 \\
\hline CP95 & 2 & 3 & 5 \\
\hline
\end{tabular}

\section{CALCULATION METHOD}

In order to establish typical levels of harmonic voltages a model of the distribution system must first be produced. The parameters required to model an MV distribution system are listed below.

- Total rated capacity and total maximum demand of HV/MV zone substation transformer.

- Fault level of HV transmission feeder to establish harmonic impedance of HV transmission system.

- Number of feeders and approximate number of distribution transformers per feeder.
- Approximate lengths and impedances of lines (either underground or overhead).

- Approximate proportion of residential, commercial and industrial loading for each feeder.

During the design process only a qualitative estimate of voltage harmonic distortion levels is required. To establish these typical levels of harmonic voltage distortion some approximations must be made to aid the calculation. The assumptions required to simplify a system such as the distribution system shown in Fig. 1 are listed below.

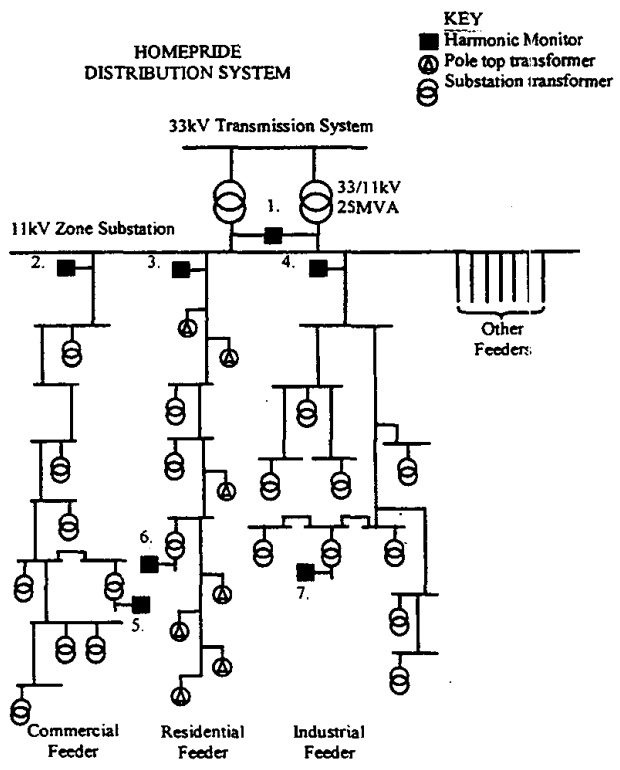

Fig.1 - MV Distribution System Layout

- The system is balanced with no zero sequence.

- The $5^{\text {th }}$ harmonic is the most significant harmonic. This is true for most balanced MV distribution systems [2-4] and is reinforced by the results of the harmonic survey completed.

- As typical distribution system feeders are less than $10 \mathrm{~km}$ in length the capacitance of the feeders is assumed negligible.

- All impedances (conductors and transformers) are considered to be inductive with the resistive component assumed negligible at the $5^{\text {th }}$ harmonic.

- $5^{\text {th }}$ harmonic currents drawn by individual loads are independent of each other and are summated using the second summation law defined by (1).

- Each feeder's residential, commercial and industrial type loads are spread out evenly over its length.

Each load type is a mixture of linear and non-linear equipment which vary throughout the day. Since the two components vary independently to some extent, the fraction $\mathrm{I}_{5} / \mathrm{I}_{1}$ will vary. We assume that the ratio of the statistics 
$I_{5}$ CP9s $/ I_{1}$ CP9s is constant for all loads of a given type (R, C and I). The constant is a number which can be found from current measurements alone at the supply point to a pure $\mathrm{R}, \mathrm{C}$ or $\mathrm{I}$ load. From the survey to be described later in Section IV, these proportions were found to be

- Residential $5^{\text {th }}$ harmonic current $I_{5 \text { CP95 }} / I_{1}$ CP9s $=0.03 \mathrm{pu}$

- Commercial $5^{\text {th }}$ harmonic current $I_{5 \text { CP9S }} / I_{1}$ CP95 $=0.07 \mathrm{pu}$

- Industrial $5^{\text {th }}$ harmonic current $\mathrm{I}_{5}$ CP95 $/ \mathrm{I}_{1 \mathrm{CP} 9 \mathrm{~S}}=0.11 \mathrm{pu}$

The first step in predicting the harmonic voltage distortion throughout a system is to estimate the level of harmonic currents. Using the number of customers per LV distribution system and number of MV substations in conjunction with the proportion of residential, commercial and industrial loads the total harmonic current drawn at the HV/MV zone substation can be determined.

The individual load harmonics are summated together as given by (2) ( $a=1.4$ for the $5^{\text {th }}$ harmonic) to find the total harmonic current drawn from the HV transmission system.

$$
\mathrm{I}_{\text {5rotal }}{ }^{1.4}=\mathrm{I}_{\text {5load } 1}{ }^{1.4}+\mathrm{I}_{\text {5load2 }}{ }^{1.4}+\mathrm{I}_{\text {sload } 3}{ }^{1.4}+\ldots
$$

The level of distortion at the MV bus of the zone substation $\left(V_{5 M V}\right)$ is then the summation of the HV background distortion $\left(V_{S \mathrm{BG}}\right)$ and the voltage distortion arising from the impedance of the HV transmission line and the HV/MV zone substation transformer $\left(\mathrm{V}_{\mathrm{SHV}}\right)$.

$$
\mathrm{V}_{S B G}{ }^{1.4}+\mathrm{V}_{S \mathrm{HV}}{ }^{1.4}=\mathrm{V}_{S M \mathrm{MV}}{ }^{1.4}
$$

If known, the background distortion level can be directly applied or else the approximation outlined in [1] can be used by assuming the distortion level at $\mathrm{HV}$ is the same proportion as the distortion level at MV when compared to the harmonic limits. For example the recommended harmonic limit for the $5^{\text {th }}$ harmonic at $\mathrm{HV}$ is $2 \%$ and for MV the limit is $5 \%$ thus the background distortion can be calculated as shown in (4).

$$
(k 2 \%)^{1.4}+\mathrm{V}_{5 \mathrm{HV}}{ }^{1.4}=(k 5 \%)^{1.4}
$$

where

$$
k=\text { existing proportion of recommended limit }
$$

From the MV zone substation the distortion levels down each stream of each of the feeders is calculated by the summation of the voltage distortions due to each of the individual loads and the background distortion. This is achieved by multiplying the harmonic current, approximated by the size of load and typical harmonic current level, with the harmonic impedance seen by that load back to the MV zone substation bus. For the $5^{\text {th }}$ harmonic, the harmonic impedance is approximated by 5 times the fundamental impedance. The process illustrating the harmonic voltage calculation is illustrated by Fig. 2 .
The harmonic voltage distortion at the connection point after impedance $X_{1}$, which is due to the $5^{\text {th }}$ harmonic currents produced by the individual loads downstream and the background distortion, is given by (5) as follows.

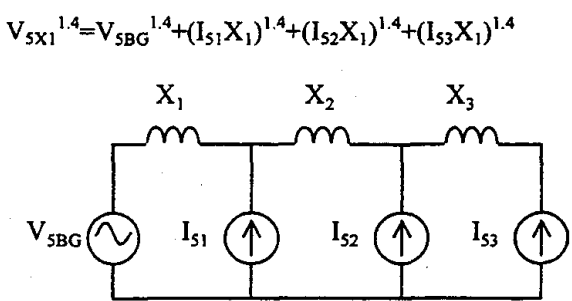

Fig. 2 - MV Feeder Equivalent Circuit for Voltage Distortion Calculation

\section{STUDY SYSTEM AND SURVEY RESULTS}

The Power Quality Centre completed a harmonic survey of part of a radial distribution system owned by Integral Energy over a period of two months. The relevant part of the system is shown in Fig. 1 and consists of 7 sites on the $11 \mathrm{kV}$ side of a zone substation and some downstream sites on the immediate secondary of the distribution transformers as it was difficult to get access to the MV feeder other than at the substation. The survey included measurement of the fundamental, $5^{\text {th }}$ harmonic, $19^{\text {th }}$ harmonic, $49^{\text {th }}$ harmonic, and total harmonic distortion for each of the three phase currents and voltages. This choice was limited by the available registers in the harmonic monitor used.

The downstream sites monitored in the survey included a low voltage (LV) residential pad mount substation transformer, an LV commercial/business substation transformer feeding a large shopping centre, an LV manufacturing industrial complex substation transformer. The upstream sites included the sending end of the feeder for each of the monitored downstream sites as well as the total current for the zone substation. The resulting weekly average $95^{\text {th }}$ percentile cumulative probability results for each of the sites are given in Table 2.

One of the assumptions in calculation of $95 \%$ harmonic voltage distortion levels is that an approximate proportion of residential loads, commercial loads and industrial loads is known. Further, typical values of harmonic currents can be assigned to each of the residential, commercial and industrial loads for calculation of the harmonic voltage distortion. The magnitudes of harmonic currents were obtained from measurements taken in the harmonic survey. The typical levels of per unit $5^{\text {th }}$ harmonic current produced by residential, commercial and industrial load types given in Section III were calculated from values in Table 2. Similar figures could be used during the design phase of similar distribution systems to establish typical harmonic levels and help identify future harmonic problems. 
Table 2

Results of harmonic survey of Integral Energy distribution system

\begin{tabular}{|c|c|c|c|c|c|}
\hline Hasmonic Monitor Site (Voltage Level) & $\mathrm{I}_{1 \mathrm{CP} 95}(\mathrm{~A})$ & $I_{S C P O s}(A)$ & $I_{19 \mathrm{CPgs}}(\mathrm{A})$ & $V_{\text {scpys }}(\%)$ & $V_{1 x \text { cpgs }}(\%)$ \\
\hline Residential Transformer (415V) & 143 & 3.01 & 0.28 & 1.48 & 0.16 \\
\hline Commercial Transformer $(415 \mathrm{~V})$ & 648 & 44.7 & 1.08 & 2.60 & 0.15 \\
\hline Industrial Transformer (415V) & 1310 & 137 & 3.35 & 1.74 & 0.15 \\
\hline Residential Feeder (11kV) & 97.8 & 3.16 & 0.36 & 1.55 & 0.17 \\
\hline Commercial Feeder (11kV) & 120 & 3.01 & 0.16 & 1.54 & 0.17 \\
\hline Industrial Feeder (11kV) & 146 & 5.78 & 0.27 & 1.54 & 0.17 \\
\hline Zone Substation Transformer (11kV) & 1180 & 18.2 & 1.43 & 1.54 & 0.16 \\
\hline
\end{tabular}

\section{APPLICATION OF METHOD TO SURVEYED} SYSTEM

The system parameters are listed below.

- Zone substation rating is 50MVA

- Typical maximum demand at $33 \mathrm{kV} / 1 \mathrm{lkV}$ zone substation transformer is $0.45 \mathrm{pu}$ (approximated by $95^{\text {th }}$ percentile of fundamental current).

- Load is approximately $30 \%$ residential, $40 \%$ commercial, $30 \%$ industrial

- 10 Feeders are equally loaded

- There are no power factor correction (PFC) capacitors installed in the system, but these should be easy to allow for in the approach given here.

- Residential feeders (classified as $85 \%$ residential load and $15 \%$ commercial load) typically consist of 10 substations

- Commercial feeders (classified as $86 \%$ commercial load and $14 \%$ residential load) typically consist of 7 substations

- Industrial feeders (classified as $75 \%$ industrial load, $20 \%$ commercial load and 5\% residential load) typically consist of 5 substations

$33 \mathrm{kV} / 1 \mathrm{kV} 50 \mathrm{MVA}$

Impedance $15 \%$

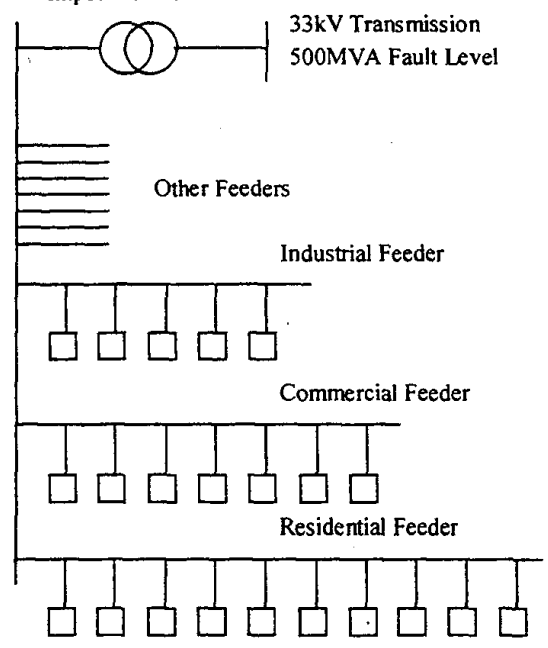

Fig. 3 - Model of MV Distribution system
The distribution model shown in Fig. 3 represents a simplified model of the surveyed MV distribution system. The residential, commercial and industrial feeders are shown with the corresponding number of distribution transformers connected. The "other feeders" consist of other residential, commercial and industrial feeders.

Except for large customers who have direct connection to the feeder (usually industrial customers), each of the MV substations will have an LV distribution system which is also owned by the utility. The LV distribution system typically consists of overhead or underground cable with lengths up to $500 \mathrm{~m}$. A layout of the LV distribution system is shown in Fig. 4. The number of customers connected to each substation will vary from site to site but the loading should remain approximately the same due to the rating of the ransformer.

Each of the feeders was modelled as a combination of residential, commercial and industrial loads. Using the typical values of harmonic currents for each load :ype, with the second summation law the total $5^{\text {th }}$ harmonic current drawn by the MV system was determined. With the total harmonic current satisfactorily matching the actual measured current the progressive harmonic voltages at points further down the system could be evaluated.

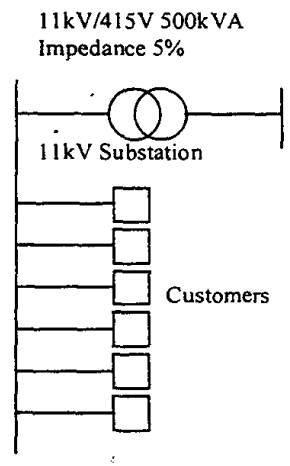

Fig. 4 - LV Distribution system layou

Comparisons of the $95^{\text {th }}$ percentile calculated results from the simulated model of the surveyed distribution system and the measured results from the harmonic survey are given in Table 3. As can be seen from the results the method used to establish typical harmonic levels gives a reassonably accurate 
account of the $95^{\text {th }}$ percentile harmonic voltage levels occurring on the MV distribution system.

Table 3

Comparison of Predicted and Field $95^{\text {th }}$ Percentile Values

\begin{tabular}{|l|l|l|}
\hline Site & Calculated & Measured \\
\hline 15 $_{\text {TOTAL }}$ & $23.2 \mathrm{~A}$ & $18.2 \mathrm{~A}$ \\
\hline V5 $_{11 \mathrm{kV} \text { BUS }}$ & $1.50 \%$ & $1.54 \%$ \\
\hline $\mathrm{VS}_{11 \mathrm{kVRES}}$ & $1.52 \%$ & - \\
\hline $\mathrm{V}_{11 \mathrm{kVCOM}}$ & $1.51 \%$ & - \\
\hline $\mathrm{V}_{11 \mathrm{kVIND}}$ & $1.53 \%$ & - \\
\hline
\end{tabular}

\begin{tabular}{|l|l|l|}
\hline $\mathrm{V5}_{415 \mathrm{VRES}}$ & $1.64 \%$ & $1.48 \%$ \\
\hline $\mathrm{V5}_{41 \text { SVCOM }}$ & $2.33 \%$ & $2.60 \%$ \\
\hline $\mathrm{V5}_{41 \text { SVIND }}$ & $1.76 \%$ & $1.74 \%$ \\
\hline
\end{tabular}

\section{SENSITIVITY RESULTS}

A sensitivity analysis of the model was completed to establish which parameters have greatest effect on the outputs of the model. The $5^{\text {th }}$ harmonic voltage level at the MV bus bar was chosen as the representative output for the analysis. Each of the input variables were increased individually by a factor of $1 \%$ and the percentage change in the output variable was established, Fig. 5 illustrates the resulting sensitivity for the $5^{\text {th }}$ harmonic voltage at the MV bus bar.

The results of the sensitivity analysis illustrate that $5^{\text {th }}$ harmonic voltage is less sensitive to errors in the "known quantities' of distribution system parameters such as line impedance, fault levels, etc., and particularly sensitive to the 'unknown quantity' of the exponent alpha $(a)$. The value used for $a$ is based on approximated statistical distributions of harmonic phase and amplitude obtained through experience [5]. Recommended values for the range of alpha for each individual harmonic are given in [1].

\begin{tabular}{|c|c|}
\hline Variable increased by $1 \%$ & $\begin{array}{l}\text { Percentage change in Zone Substation } \\
5^{\text {th }} \text { harmonic voltage }(\%)\end{array}$ \\
\hline Residertial Load (VA) & $0.064 \%$ \\
\hline Commercial Lad (VA) & $0.414 \%$ \\
\hline Industrial Load(VA) & $0.523 \%$ \\
\hline Alpha $(a)$ & Whasple $-3.321 \%$ \\
\hline$X_{f}+X_{1}$ (System fault level \& zone sub transformer) & $1.000 \%$ \\
\hline$X_{i}$ (Zone substation transformer) & $0.630 \%$ \\
\hline Number substations per foeder & $-0.284 \%$ \\
\hline Residertial $\left(\mathrm{I}_{5 \text { CPys }} / \mathrm{I}_{\mathrm{H} \text { (PSs }}\right)$ & $0.064 \%$ \\
\hline Commercial $\left(\mathrm{l}_{\mathrm{SCPS}} / \mathrm{l}_{\mathrm{lCPS})}\right)$ & $0.414 \%$ \\
\hline Industrial ( $\left.l_{\text {scross }} / l_{10 \text { coss }}\right)$ & $0.523 \%$ \\
\hline All load types ( $\left.\mathrm{I}_{\mathrm{scos}} / \mathrm{I}_{\mathrm{ICPys}}\right)$ & $1.000 \%$ \\
\hline Residential Load (\%) & $0.792 \%$ \\
\hline Commercial Load (\%) & $0.397 \%$ \\
\hline Industrial Load (\%) & $0.830 \%$ \\
\hline
\end{tabular}

Fig 5-Sensitivity of $5^{\text {th }}$ Harmonic Voltage

Although the distribution system surveyed showed good correlation with the calculated results from the model, the sensitivity analysis highlights the need for an appropriate value for $a$ to be used. Where possible, measurements of harmonic amplitude and phase should be obtained to confirm an approximate uniform distribution for the lower order harmonics.

As the model output has shown greatest sensitivity to the value of $a$, a further study into the change in output over the full range of $a$ was completed. As expected the relationship of the magnitude of $a$ to error in the output was exponential. Fig. 6 illustrates the exponential relationship for percentage change in the output depending on the value of $a$ used. If the diversity of the individual harmonics was not considered, direct addition of harmonic components $(a=1)$ would largely over estimate the resulting value for the $5^{\text {th }}$ harmonic voltage.

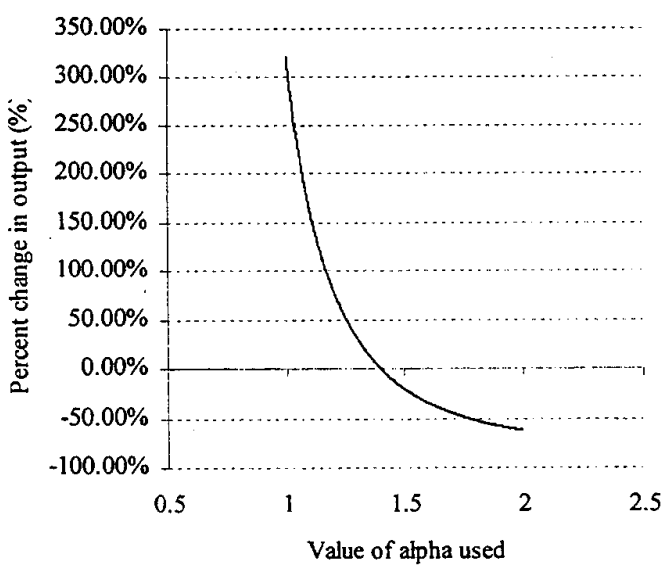

Fig. $6-5^{\text {th }}$ Harmonic Voltage Sensitivity to Alpha

\section{CONCLUSION}

The second summation law, defined by (1), has proven to be a useful technique for summing voltage distortion levels within a distribution system when diversity amongst sampled data exists.

By assigning typical harmonic currents to residential, commercial and industrial load types, a simplified harmonic analysis of voltage distortion levels within a distribution system can be completed. The benefit of this analysis is that only a reduced order of system data is required to produce reasonably accurate results. This technique is applicable to most radial MV distribution systems. The harmonic prediction technique has proven to be successful when compared to actual harmonic measurements obtained from a survey of a suburban MV radial distribution system. The use of such a technique will enable distribution system designers to better understand the harmonic capabilities of distribution systems.

Calculation of harmonic impedances through MV feeders and LV distribution show that most voltage distortion arising from harmonic currents will be produced in the LV distribution system. This suggests that the harmonic 
impedances of all components in a distribution system should be considered during the design phase to help minimise the effects of harmonic currents produced by distorting loads.

Estimation of harmonic voltage levels within radial distribution systems using the second summation law from [1] has shown to be successful. The value of alpha $(a)$ recommended by [1] has produced good results for the study system in this case, but a sensitivity analysis has illustrated that $a$ needs to be chosen carefully.

\section{ACKNOWLEDGMENTS}

The authors are grateful for the technical and financial support provided by Integral Energy.

\section{REFERENCES}

[1] AS/NZS 610003.6 (Draft) "Electromagnetic compatibility. Part 3.6: Limits- Assessment of emission limits for distorting loads in MV and HV power systems"

[2] I.Nejdawi, A.Emanuel, D.Pileggi, M.Corridori, R.Archambeault, "Harmonics Trend in NE USA: A Preliminary Survey", IEEE Trans. on Power Delivery, Vol.14, No.4, October 1999

[3] R.G.Wilkie, G.E.Dowd, "Harmonic Measurements in Industrial Applications", AUPEC'93, $29^{\text {th }}$ September $-1^{\text {st }}$ October 1993, University of Wollongong, Australia

[4] A.Emanuel, J.Orr, D.Cyganski, E.Gulachenski, "A Survey of Harmonic Voltages and Currents at Distribution Substations", IEEE Trans. on Power Delivery, Vol.6, No.4, October 1991

[5] J.M.Crucq, A.Robert, "Statistical Approach for Harmonics Measurements and Calculations", CIRED 1989, Paper 2.02

\section{BIOGRAPHIES}

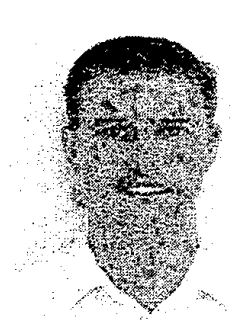

Duane Robinson: Mr Robinson graduated from the University of Wollongong with a $\mathrm{BE}$ (Hons 1) degree in 1998 after completing a seven year cadetship with the BHP Port Kembla Steelworks. Mr Robinson currently is sponsored by the Integral Energy Power Quality Centre to complete his $\mathrm{PhD}$ degree. His $\mathrm{PhD}$ research project is concerned with the study of harmonic distortion within distribution systems and related mitigation techniques.

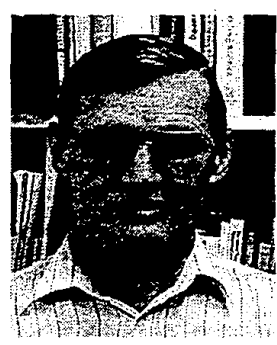

Victor J Gosbell: Dr Gosbell obtained his BE degree in 1966 and his $\mathrm{PhD}$ in 1971 from the University of Sydney. In 1973 he commenced lecturing at the University of Sydney and in 1990 took up the position of Associate Professor at the University of Wollongong where he is working on power electronic simulation, harmonics and power quality. He is a Fellow of the Institution of Engineers, Australia and the immediate pastChairperson of the Australasian Committee for Power Engineering.

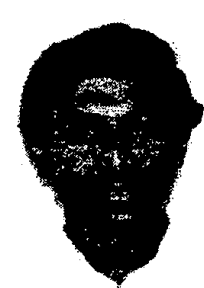

Sarath Perera: Dr Perera graduated from the University of Moratuwa, Sri Linka with a BSc (Eng) degree (1974) specialising in Electrical Power. He obtained his MEngSc degree (1978) from the University of New South Wales and the $\mathrm{PhD}$ degree (1988) from th: University of Wollongong. He was an academic at the University of Moratuwa, Sri Lanka for nearly 12 years and is now a Senior Lecturer at the University of Wollongong. His research interests are in Power Quality.

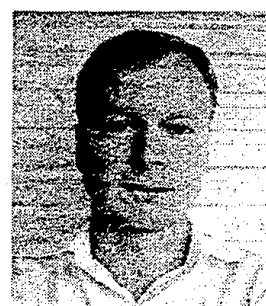

Damian Mannix: Mr Mannix obtained his BE (Hons) degree from the University of Wollongong in 1997. Mr Mannix joined the Integral Energy Power Quality Centre as a Research Associate in 1998 after working with Integral Energy (formerly lllawarra Electricity) for 12 years. He is currently involved with the testing of power quality instruments, harmonic studies of distribution systems and harmonic distortion monitoring projects. 